\title{
Practice of moderate physical activity can attenuate the loss of lean body mass in menopausal women
}

\author{
A prática de atividade física moderada pode atenuar a perda de massa \\ magra em mulheres na menopausa
}

\author{
Tiego A. Diniz ${ }^{1,2 *}$, Diego G.D. Christofaro ${ }^{3}$, Vanessa R. dos Santos ${ }^{1}$, Juliana Viezel ${ }^{1}$, Ca- \\ mila Buonani ${ }^{1}$, Fabricio E. Rossi ${ }^{1,2}$, Ismael F. Freitas Junior ${ }^{1}$
}

ARTIGO ORIGINAL | ORIGINALARTICLE

\begin{abstract}
The aim of this study was to analyze the relationship between physical activity (PA) and total body (BLM), leg (LLM) and arm lean mass (ALM) in menopausal women. Sixty two 62 menopausal women were included (61.2 \pm 7.6 years). Their practice of PA was assessed by Actigraph GT3X accelerometer, and is reported as minutes per week of light or moderate-vigorous PA, and total PA. The sample was dichotomized into two groups according to their weekly practice of PA moderate-vigorous; physically active ( $\geq 150$ minutes) and insufficiently active ( $<150$ minutes). Body composition measures were assessed by DXA and were reported as percentages. Comparisons between the groups of PA and total and segmental lean body mass were performed by independent $t$ test. Association between the tertile of BLM and the groups of PA were performed by chi-square test. Physically active women showed significantly higher mean values for BLM $(52.8 \pm 5.4$ vs $49.8 \pm 4.7 ; \mathrm{p}=0.028)$ and LLM $(17.1 \pm 2.2$ vs $15.9 \pm 1.8$; $\mathrm{p}=0.026)$, whereas the difference in the ALM was not significant. When the BLM was categorized into tertiles, it was significantly greater in physically active women (higher tertile $=44.7 \%$ ), compared with the insufficiently active women (higher tertile $=16.7 \%$ ). Menopausal women who spent more minutes engaged in moderate-vigorous PA can showed higher BLM and LLM.
\end{abstract}

Keywords: menopause, women, motor activity, accelerometry, skeletal muscle, health.

RESUMO

O objetivo do presente estudo foi analisar a relação da atividade física (AF) e massa corporal magra total (BLM), de pernas (LLM) e braços (ALM) em mulheres na menopausa. Participaram do estudo 62 mulheres (61.2 \pm 7.6 anos). A pratica habitual de AF foi avaliada através do acelerômetro marca Actigraph GT3X e foi expressa em minutos por semana de AF leve e moderada-vigorosa, e AF total. A amostra foi dicotomizada em dois grupos de acordo com a prática semanal de AF moderada-vigorosa; grupo fisicamente ativo ( $\geq 150$ minutos) e insuficientemente ativo ( $<150$ minutos). A medidas de composição corporal foram estimadas utilizando o DEXA e foi reportada como percentual. A comparação entre os grupos de AF e a massa corporal magra total e segmentar foram realizadas pelo test $\mathrm{t}$ independente. A associação entre os tercis de BLM e os grupos de AF foi realizado pelo Qui-quadrado. O grupo fisicamente ativo apresentou maiores valores médios para BML (52.8 \pm 5.4 vs 49.8 $\pm 4.7 ; p=0.028)$ e LLM $(17.1 \pm 2.2$ vs $15.9 \pm 1.8 ; \mathrm{p}=0.026)$, enquanto que a diferença para ALM não foi estatisticamente diferente. Quando o BLM foi categorizado em tercis, $44.7 \%$ das mulheres fisicamente ativas se encontravam no tercil superior, enquanto que apenas $16.7 \%$ das insuficientemente ativas se encontravam nesse tercil. Mulheres na menopausa que despende maior tempo tempo em AF moderada-vigorosa podem apresentar maiores valores de massa corporal magra total e segmentar.

Keywords: menopausa, mulheres, atividade motora, acelerometria, músculo-esquelético, saúde.

Manuscript received in April $8^{\text {th }}, 2014$; Accepted June $3^{\text {rd }}, 2014$

${ }^{1}$ Center of Studies and Laboratory of Evaluation and Prescription of Motor Activities (CELAPAM), Department of Physical Education, Sao Paulo State University (UNESP), 19060-900, Presidente Prudente, SP, Brazil.

${ }^{2}$ Exercise and Immunometabolism Research Group, Department of Physical Education, Sao Paulo State University (UNESP), 19060-900, Presidente Prudente, SP, Brazil.

${ }^{3}$ Study Group of Physical Activity and Health, Sao Paulo State University, Presidente Prudente, Brazil

* Corresponding Author. Department of Physical Education, São Paulo State University, UNESP, Rua Roberto Simonsen, 305, 19060-900 Presidente Prudente, SP, Brazil. Email: tiegodiniz@gmail.com 


\section{INTRODUCTION}

With the demographic transition which has occurred in recent decades due to lower mortality and fertility rates, population life expectancy has increased dramatically, resulting in a population which is growing older (Carvalho \& Rodríguez-Wong, 2008). In women, this growth is greater than men because their life expectancy is higher (Luy \& Gast, 2014).

Aging is a continuous process in which morphological and functional declines occur, such as decreased lean body mass, bone and functional capacity (Buffa, Floris, Putzu, \& Marini, 2011; Penha, Piçarro, Neto, \& De, 2012; Roubenoff \& Hughes, 2000), factors which may contribute significantly to an increase in the risk of falls and fractures (Mazo, Liposcki, Ananda, \& Prevê, 2007), as well as negative changes in the metabolic profile (Lara, Casanova, \& Spritzer, 2010). In the case of women, these aging consequences are intensified with menopause, a period characterized by the disruption of menstrual cycles and loss of ovarian function (World Health Organization, 1996).

A decrease in lean body mass can be attributed to changes in muscle components, such as decreases in the number and size of muscle fibers and loss of complete motor units, having motor neuron, axon, and all innervated muscle fibers (Zhong, Chen, \& Thompson, 2007). Another variable to be considered in the aging process is insufficient physical activity practice. Insufficiently active individuals tend to have lower values for lean body mass and a higher prevalence of reduced functional capacity, because regular practice of physical activity throughout life slows muscle loss and contributes to the conservation of functional capacity (Abe et al., 2012; Kamel, 2003). Thus, physical activity becomes an effective strategy for maintaining lean body mass, preventing falls and lowering functional dependence.

The literature contains few studies that have analyzed the relationship between physical activity practice and lean body mass (Buonani et al., 2013; Park, Park, Shephard, \& Aoyagi,
2010), and in addition, there are a lack of studies that have investigated these aspects in menopausal women using accurate instruments to measure physical activity.

Thus, the aim of this study was to analyze the influence of physical activity, using accelerometry, on total and segmental lean body mass in menopausal women aged over 50 years.

\section{METHOD}

\section{Participants}

The sample consisted of sixty-two postmenopausal women aged 50-79 (mean 61.2 \pm 7.6 years), who were engaged in an exercise program promoted by the Department of Physical Education of the Universidade Estatual Paulista (UNESP), located in the city of Presidente Prudente, São Paulo, Brazil. To be eligible, the women had to meet the following inclusion criteria: 1) female, 2) postmenopausal (no menstruation for 1 year or more) (WHO, 1996), 3) aged 50 years or more on the date of the assessment, 4) be overweight (\%BF $\geq 35$ ) (Bouchard, Dionne, \& Brochu, 2009), 5) no practice of regular exercise for a period of 6 months prior to the valuation date, 6) no use of hormone therapy. The present study reports only the baseline measures of the exercise program. Initially, 67 women agree to participate in the study, however, five were excluded because measures from the accelerometer data were not complete. All participants gave written informed consent, and the study protocol was reviewed and approved by the Ethical Research Committee of UNESP (number 64/2011).

\section{Instruments}

\section{Anthropometry and Body composition}

Height was measured in the upright position to the nearest 0.1 centimeter without shoes using a wall-mounted stadiometer (Sanny, São Bernardo do Campo, São Paulo, Brazil). Body mass was measured with a calibrated electronic scale (Filizola, model Personal Line, São Paulo, Brazil) with a precision of 0.1 kilogram.

Body lean mass was assessed using dual energy X-ray absorptiometry (DXA) (Lunar, DPX- 
MD, software 4.7) and is reported as percentages. This device provides lean mass percentage divided by body segments (upper limbs, trunk, legs and arms), which allowed for the analysis performed in this study.

\section{Procedures}

Physical activity

The practice of habitual physical activity was measured using accelerometers (ActiGraph GT3X, Pensacola, FL), which can be used to objectively measure the duration and intensity of physical activity under free-living conditions. The devices are small (size $3.8 \mathrm{~cm} \times 3.7 \mathrm{~cm} \mathrm{x}$ $1.8 \mathrm{~cm})$ and lightweight $(27 \mathrm{~g})$, and are designed to record movements in the anteroposterior, mediolateral, and vertical orthogonal planes. ActiGraphGT3X accelerometer measures and records changes in acceleration whose magnitudes cover approximately 0.05$2.5 \mathrm{~g}\left(\mathrm{~g}=9.8 \mathrm{~m} / \mathrm{s}^{2}\right)$ within a frequency range of 0.25- 2.5 Hertz, and it is digitized by an Analogue-Digital converter 12 bit at a rate of 30 times per second $(30 \mathrm{~Hz})$. The sampling interval was set at 60 seconds (epoch). For this study population we chose this period of epoch because the pattern of physical activity is related to low intensity and long duration (Trost, McIver, \& Pate, 2005).

Each accelerometer was attached to an elastic belt and was securely positioned near the right iliac crest. The participants used the equipment for eight days consecutively, of which seven were full days, and were instructed to wear the accelerometer while awake, and to remove it for water activities.

Initially, specific software (The ActiLife5 Data Analysis Software by Actigraph) was used to analyze the data, and only full days of monitoring were included in the database. Secondly, zero hours consecutive counts were excluded from the analysis as they were considered to be periods when the participants were not wearing the device and days containing less than ten hours of monitoring, as these would have had the power to increase the variability (Craig et al., 2003). Finally, each participant wore the accelerometer for at least five full days (Trost et al., 2005).

Intensity levels were analyzed according to the recommendation established by Sasaki, John and Freedson (2011) for a triaxial accelerometer. Light physical activity ( $<3$ METs) was defined as less than 2690 counts per minute, moderate physical activity was defined as between 2690 and 6166 counts per minute (3.05.9 METs), and vigorous physical activity was defined as greater than 9642 counts per minute (>9.0 METs). Practice of physical activity was expressed in minutes per week of light physical activity, moderate to vigorous physical activity and total counts of physical activity (gross values established by three-axis vector magnitude).

Women were considered insufficiently active if they accumulated fewer than 150 minutes of moderate-vigorous physical activity, whilst women who accumulated 150 minutes or more of moderate-vigorous physical activity were considered physically active, according to the recommendations of the American College of Sports Medicine (ACSM) (Haskell et al., 2007).

\section{Statistical analysis}

All data were analyzed using BioEstat (version 5.0) and statistical significance was set at the $p<0.05$ level. Characteristics of the sample were described by mean (standard deviation) and median (interquartile range) using the Kolmogorov-Smirnov test. The Independent $t$ test was used to compare habitual physical activity (physically active and insufficiently active) and total body, leg and arm lean mass. Chi-square was used after we divided subjects arbitrarily into increasing tertiles of total lean body mass (T1-T3), in percentages, to verify the statistical significance of associations between lean body mass and physical activity. In addition, we performed the odds ratio of this association by the Binary Logistic Regression to analyze the magnitude of possible associations between physical activity and lean mass. 


\section{RESULTS}

The anthropometry, body composition and physical activity characteristics of the study participants are listed in table 1 . The mean age of the women was $61.2 \pm 7.6$ years. The median BMI was in the overweight range $\left(28.9 \mathrm{~kg} / \mathrm{m}^{2}\right)$. Women preferred light physical activity $(8429.2$ [503.1] minutes per week), which accounted for $98.1 \%$ of total physical activity, however, over half of the participants practiced a value of greater than 150 minutes per week of moderatevigorous physical activity (61.3\%), meeting the recommendations proposed by the ACSM for health improvements (Haskell et al., 2007).

Table 1

Descriptive Statistics $(n=62)$

\begin{tabular}{lc}
\hline \multicolumn{1}{c}{ Variables } & Mean \pm SD \\
\hline Age (years) & $61.2 \pm 7.6$ \\
Height $(\mathrm{cm})$ & $156.1 \pm 7.1$ \\
Weight $(\mathrm{kg})$ & $71.1 \pm 14.1$ \\
BMI $\left(\mathrm{kg} / \mathrm{m}^{2}\right) \dagger$ & $28.9(8.2)$ \\
$\quad$ Body composition & \\
Total body lean mass $(\%)$ & $51.7 \pm 5.3$ \\
Leg lean mass $(\%)$ & $16.6 \pm 2.1$ \\
Arm lean mass $(\%)$ & $5.8 \pm 0.8$
\end{tabular}

\section{Physical activity}

Total (counts)

Light (min/week) $\dagger$

Mod+vig (min/week) $\dagger$

Note: $\uparrow$ Median(Interquartile range); SD - standard deviation; BMI - body mass index; Mod+Vig - Plus moderate and vigorous physical activity; min/week - minutes per week; kg

- kilogram; $\mathrm{m}^{2}$ - meters raised to the second power.

Although the median of moderate-vigorous physical activity was higher than the recommendations of the ACSM (Haskell et al., 2007), $38.7 \%$ of women were below the recommended threshold, as well as $53.2 \%$ who did not practice any vigorous physical activity. In contrast, sixteen women $(25.8 \%)$ practiced 300 or more minutes per week of moderate-vigorous physical activity, achieving a higher value than that recommended.
Figures 1, 2 and 3 represent the comparison of the average percentages of total body, leg and arm lean mass, respectively, between women who were physically active and insufficiently active. Physically active women showed significantly higher mean values for total lean body mass $(52.8 \pm 5.4$ vs $49.8 \pm 4.7 ; \mathrm{p}=0.028)$ and leg lean mass $(17.1 \pm 2.2$ vs $15.9 \pm 1.8 ; \mathrm{p}=$ $0.026)$, whereas the difference in arm lean mass was not significant $(5.9 \pm 0.8$ vs $5.5 \pm 0.8 ; \mathrm{p}=$ 0.082).

\section{Total lean body mass}

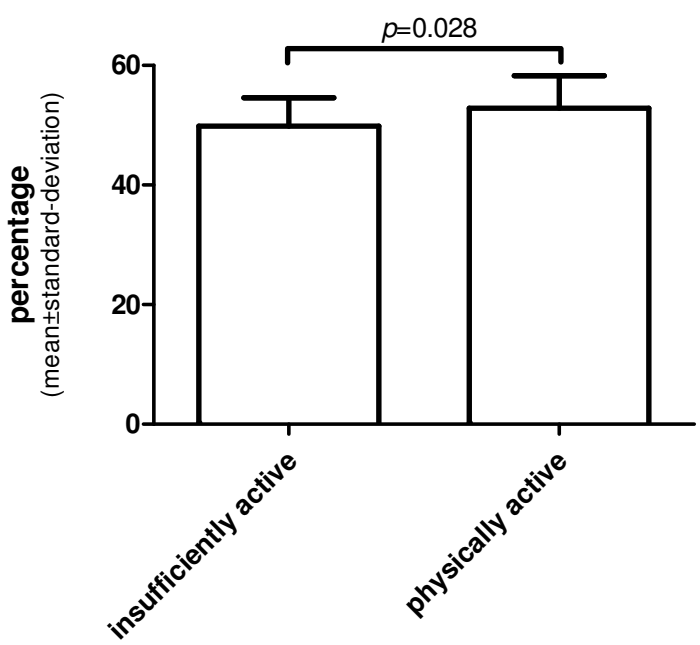

Figure 1. Percentages of total lean body mass of women who were insufficiently active and physically active

When we analyze the association between physical activity and increasing tertiles of percentage of total lean body mass, by Chi-square test, we found that those who were in the higher tertile were, predominantly, physically active ( $\mathrm{p}$ $=0.042$ ). Moreover, the odds ratio, in table 2 , showed that who were physically active had 4.2 times more chance to have greater lean mass $(\mathrm{OR}=4.250 ; 95 \% \mathrm{CI}=1.050-17.202)$. 


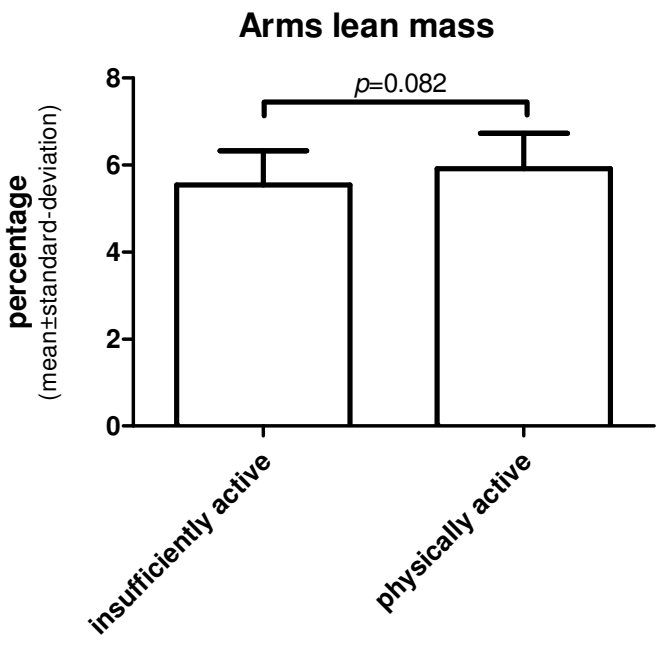

Figure 2. Percentages of arm lean mass of women who were insufficiently active and physically active
Legs lean mass

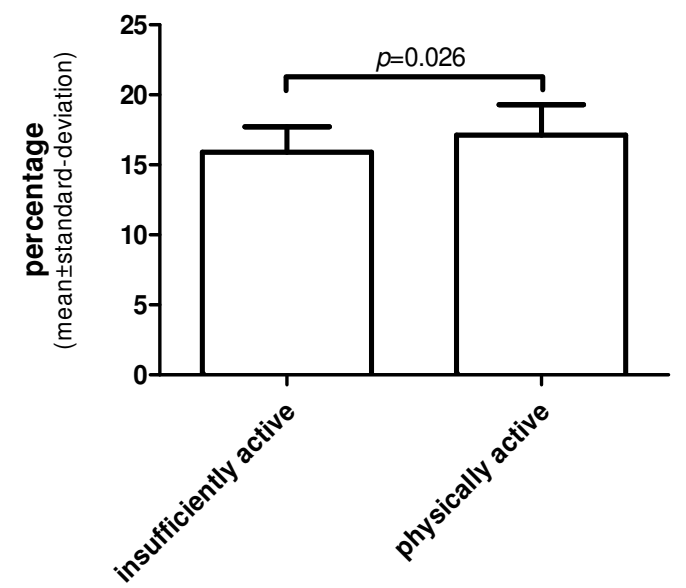

Figure 3. Percentages of leg lean mass of women who were insufficiently active and physically active

Table 2

Association between physical activity and total lean body mass

\begin{tabular}{cccc}
\hline Total lean body mass (\%) & \multicolumn{3}{c}{ Physical activity } \\
\hline & Physically active & Insufficiently active & OR (95\%CI) \\
$1^{\circ}$ tertile & $26.3 \%$ & $41.7 \%$ & 1.00 \\
$2^{\circ}$ tertile & $28.9 \%$ & $41.7 \%$ & $1.10(0.323-3.746)$ \\
$3^{\circ}$ tertile & $44.7 \%$ & $16.7 \%$ & $4.250(1.050-17.202)$ \\
\hline
\end{tabular}

Note: OR - odds ratio; CI - confidence interval.

\section{DISCUSSION}

In this cross-sectional study on the influence of physical activity on total body, leg and arm lean mass, we found that the women who spent 150 or more minutes per week engaged in moderate-vigorous physical activity showed higher values of total body and leg lean mass.

In a study on the elderly, Raguso et al. (2006) obtained similar findings to ours in the baseline period, whereby $47 \%$ of women were classified as active, achieving an average of 90 minutes per week of moderate-vigorous physical activity, and the women who had a $10 \%$ increase in energy expenditure derived from moderate-vigorous physical activity were able to increase lean body mass by up to $0.5 \mathrm{~kg}$. It is known that menopausal women showed, approximately, a $3 \mathrm{~kg}$ loss of lean body mass compared to pre-menopausal women (Poehlman et al., 1995). Thus as little as $500 \mathrm{~g}$ increase of lean body mass may decrease the risk of falls and fractures, promoting greater functional independence and quality of life.

Genton et al. (2011) studied the impact of physical activity on the body composition of elderly men and women over a period of nine years, and although our study lasted only 8 days, they found similar data to ours. When they compared the women who either increased or decreased their physical activity over the nine years, they observed that the increased physical activity group showed less weight loss; and although this group presented a reduction in lean body mass, it was lower when compared to the decreased physical activity group over the nine years, showing that physical activity may be an interesting strategy to mitigate reductions in lean body mass.

Similarly, Hansen and Alen (2002) in a transversal study with menopausal women found no statistical significance between the total lean body mass of women who practiced a 
higher mean value of physical activity compared to those with lower values $(41.8 \pm 4.3$ vs 41.1 $\pm 4.3)$. Levels of physical activity were classified by a semi-structured interview that contained questions about the type, frequency, duration and intensity of physical activity during the six months prior to the study.

These conflicting results may be due to the limitation of the instruments used to measure habitual physical activity, as questionnaires are difficult to apply in this population, as short and long term memory are limited, and cognitive loss is also common (Park et al., 2010; Shephard, 2003). Moreover, it emphasizes that different types of questionnaires may have distinct cut-off points to categorize a subject as active or not, when compared to other questionnaires, and this fact can also influence the results. Again, our accelerometer measures lasted only days, but group differences were evident.

However, Park, Park, Shephard and Aoyagi (2011), in a study with the elderly using instruments similar to the present study, had similar findings to ours. The authors found that the sarcopenic group accumulated fewer steps per day, as well as, lower values of moderate-vigorous physical activity, when compared with the nonsarcopenic group. In addition, when the minutes of moderate-vigorous physical activity were divided into quartiles, and adjusted for age, they found that women in the upper quartile had higher values of muscle mass compared with those in the lower quartiles.

Several physiological processes may explain this higher amount of lean body mass in women with higher levels of physical activity (Walrand, Guillet, Salles, Cano, \& Boirie, 2011). One possible factor is that by having an increased volume and intensity of physical activity they may have lower circulating concentrations of inflammatory markers such as interleukin- 6 and C-reactive protein, as seen by Reuben, Judd-Hamilton, Harris and Seeman (2003) in the elderly, and these in turn are responsible for muscle degradation (Schaap, Pluijm, Deeg, \& Visser, 2006).
Lean body mass is one of the variables which can be used for mortality indication (Bunout, de la Maza, Barrera, Leiva, \& Hirsch, 2011) and decreased functional capacity, which in turn is highly prevalent in older individuals and confers an increased risk of falls and fractures, increasing the number of hospitalizations and use of public health services (Mazo et al., 2007). Furthermore, during menopause an aggravation of this situation occurs, in that, during this period a marked decrease in lean body mass can be observed, frequently occasioned by non-modifiable factors such as age, endocrine changes, oxidative stress, and modifiable factors, such as the poor practice of physical activity (Maltais, Desroches, \& Dionne, 2009) and inadequate dietary intake, essentially, amino acids (Short \& Nair, 2000).

Some limitations of this study should be mentioned. Firstly, the cross-sectional design does not allow any inference of cause and effect considering the short time of evaluation (eight days). Secondly, the small sample size indicates that caution should be applied when extrapolating the results to the general population. Finally, the time spent in different intensities of physical activity should be considered approximate as there is no clear consensus of an optimal cut-off point for the study population. However, despite these limitations we suggest that physically active women can show greater amounts of lean body mass and it can reflect positively on their quality of life.

However, the positive aspects of this research should be emphasized. The measurement of physical activity using a triaxial accelerometer, thereby excluding the error of self-reported measuring, decreases the chance of misclassification of light, moderate and vigorous physical activity, inherent in questionnaires (Shephard, 2003). Furthermore, the estimation of total and segmented body composition by DXA is a strength of the study, as it is a reliable and high precision method for assessing the studied population and allows for analysis by body grouping (Woodrow, 2009). Additionally, the difficulty of comparison with other studies 
that used similarly accurate instruments, demonstrates that the practice of physical activity and its relationship to total lean body mass, especially segmented, has been little studied in premenopausal women.

\section{CONCLUSION}

In summary, the results observed in this study suggest that the practice of moderate-vigorous habitual physical activity with a weekly volume of 150 minutes, or more, can help to ease the loss of total body and leg lean mass in menopausal women. Thus, strategies aimed at providing the opportunity for menopausal women to engage in physical activities becomes important, both for improving quality of life, and from the point of view of public health.

\section{Acknowledgments:}

Nothing to declare.

\section{Conflict of interest:}

Nothing to declare.

\section{Funding:}

Nothing to declare.

\section{REFERÊNCIAS}

Abe, T., Mitsukawa, N., Thiebaud, R. S., Loenneke, J. P., Loftin, M., \& Ogawa, M. (2012). Lower body site-specific sarcopenia and accelerometer-determined moderate and vigorous physical activity: the HIREGASAKI study. Aging Clinical and Experimental Research, 24(6), 657-662. http://doi.org/10.3275/8758

Bouchard, D. R., Dionne, I. J., \& Brochu, M. (2009). Sarcopenic/obesity and physical capacity in older men and women: data from the Nutrition as a Determinant of Successful Aging (NuAge)the Quebec longitudinal Study. Obesity (Silver Spring, Md.), 17(11), 2082-2088. http://doi.org/10.1038/oby.2009.109
Buffa, R., Floris, G. U., Putzu, P. F., \& Marini, E. (2011). Body composition variations in ageing. Collegium Antropologicum, 35(1), 259-265.

Bunout, D., de la Maza, M. P., Barrera, G., Leiva, L., $\&$ Hirsch, S. (2011). Association between sarcopenia and mortality in healthy older people. Australasian Journal on Ageing, 30(2), 89-92. http://doi.org/10.1111/j.1741-

6612.2010.00448.x

Buonani, C., Rosa, C. S. da C., Diniz, T. A., Christofaro, D. G. D., Monteiro, H. L., Rossi, F. E., ... Forte, I. (2013). Prática de atividade física e composição corporal em mulheres na menopausa. Revista Brasileira de Ginecologia e Obstetrícia, 35(4), 153-158. http://doi.org/10.1590/S010072032013000400004

Carvalho, J. A. M. de, \& Rodríguez-Wong, L. L. (2008). A transição da estrutura etária da população brasileira na primeira metade do século XXI. Cadernos de Saúde Pública, 24(3), 597$605 . \quad$ http://doi.org/10.1590/S0102311X2008000300013

Craig, C. L., Marshall, A. L., Sjöström, M., Bauman, A. E., Booth, M. L., Ainsworth, B. E., ... Oja, P. (2003). International physical activity questionnaire: 12 -country reliability and validity. Medicine and Science in Sports and Exercise, 35(8), 1381-1395.

http://doi.org/10.1249/01.MSS.0000078924.6 1453.FB

Genton, L., Karsegard, V. L., Chevalley, T., Kossovsky, M. P., Darmon, P., \& Pichard, C. (2011). Body composition changes over 9 years in healthy elderly subjects and impact of physical activity. Clinical Nutrition, 30(4), 436-442. http://doi.org/10.1016/j.clnu.2011.01.009

Hansen, R. D., \& Allen, B. J. (2002). Habitual physical activity, anabolic hormones, and potassium content of fat-free mass in postmenopausal women. The American Journal of Clinical Nutrition, 75(2), 314-320.

Haskell, W. L., Lee, I.-M., Pate, R. R., Powell, K. E., Blair, S. N., Franklin, B. A., ... American Heart Association. (2007). Physical activity and public health: updated recommendation for adults from the American College of Sports Medicine and the American Heart Association. Circulation, 116(9), 1081-1093. http://doi.org/10.1161/CIRCULATIONAHA.107.185649 
Kamel, H. K. (2003). Sarcopenia and Aging. Nutrition Reviews, 61(5), 157-167. http://doi.org/10.1301/nr.2003.may.157-167

Lara, S., Casanova, G., \& Spritzer, P. M. (2010). Influence of habitual physical activity on body composition, fat distribution and metabolic variables in early postmenopausal women receiving hormonal therapy. European Journal of Obstetrics, Gynecology, and Reproductive Biology, 150(1), 52-56. http://doi.org/10.1016/j.ejogrb.2010.02.007

Luy, M., \& Gast, K. (2014). Do women live longer or do men die earlier? Reflections on the causes of sex differences in life expectancy. Gerontology, $60(2)$, 143-153. http://doi.org/10.1159/000355310

Maltais, M. L., Desroches, J., \& Dionne, I. J. (2009). Changes in muscle mass and strength after menopause. Journal of Musculoskeletal \& Neuronal Interactions, 9(4), 186-197.

Mazo, G. Z., Liposcki, D. B., Ananda, C., \& Prevê, D. (2007). Condições de saúde, incidência de quedas e nível de atividade física dos idosos. Brazilian Journal of Physical Therapy, 11(6), 437-442. http://doi.org/10.1590/S141335552007000600004

Park, H., Park, S., Shephard, R. J., \& Aoyagi, Y. (2010). Yearlong physical activity and sarcopenia in older adults: the Nakanojo Study. European Journal of Applied Physiology, 109(5), 953-961. http://doi.org/10.1007/s00421-0101424-8

Penha, J. C. L., Piçarro, I. da C., Neto, B., \& De, T. L. (2012). Evolução da aptidão física e capacidade funcional de mulheres ativas acima de 50 anos de idade de acordo com a idade cronológica, na cidade de Santos. Ciência \& Saúde Coletiva, 17(1), 245-253. http://doi.org/10.1590/S141381232012000100027

Poehlman, E. T., Toth, M. J., Fishman, P. S., Vaitkevicius, P., Gottlieb, S. S., Fisher, M. L., \& Fonong, T. (1995). Sarcopenia in aging humans: the impact of menopause and disease. The Journals of Gerontology. Series A, Biological Sciences and Medical Sciences, 50 Spec No, 73-77. http://doi.org/10.1093/gerona/50A.Special_Issue. 73

Raguso, C. A., Kyle, U., Kossovsky, M. P., Roynette, C., Paoloni-Giacobino, A., Hans, D., ... Pichard, C. (2006). A 3-year longitudinal study on body composition changes in the elderly: role of physical exercise. Clinical Nutrition (Edinburgh,
Scotland), 25(4), 573-580.

http://doi.org/10.1016/j.clnu.2005.10.013

Reuben, D. B., Judd-Hamilton, L., Harris, T. B., \& Seeman, T. E. (2003). The associations between physical activity and inflammatory markers in high-functioning older persons: MacArthur studies of successful aging. Journal of the American Geriatrics Society, 51(8), 1125-1130. http://doi.org/10.1046/j.1532-

5415.2003.51380.x

Roubenoff, R., \& Hughes, V. A. (2000). Sarcopenia Current Concepts. The Journals of Gerontology Series A: Biological Sciences and Medical Sciences, 55(12), M716-M724. http://doi.org/10.1093/gerona/55.12.M716

Sasaki, J. E., John, D., \& Freedson, P. S. (2011). Validation and comparison of ActiGraph activity monitors. Journal of Science and Medicine in Sport / Sports Medicine Australia, 14(5), 411416.

http://doi.org/10.1016/j.jsams.2011.04.003

Schaap, L. A., Pluijm, S. M. F., Deeg, D. J. H., \& Visser, M. (2006). Inflammatory markers and loss of muscle mass (sarcopenia) and strength. The American Journal of Medicine, 119(6), 526.e9-17. http://doi.org/10.1016/j.amjmed.2005.10.049

Shephard, R. J. (2003). Limits to the measurement of habitual physical activity by questionnaires. British Journal of Sports Medicine, 37(3), 197206. http://doi.org/10.1136/bjsm.37.3.197

Short, K. R., \& Nair, K. S. (2000). The effect of age on protein metabolism. Current Opinion in Clinical Nutrition and Metabolic Care, 3(1), 3944.

Trost, S. G., McIver, K. L., \& Pate, R. R. (2005). Conducting accelerometer-based activity assessments in field-based research. Medicine and Science in Sports and Exercise, 37(11 Suppl), S531-S543.

Walrand, S., Guillet, C., Salles, J., Cano, N., \& Boirie, Y. (2011). Physiopathological mechanism of sarcopenia. Clinics in Geriatric Medicine, 27(3), 365-385.

http://doi.org/10.1016/j.cger.2011.03.005

Woodrow, G. (2009). Body composition analysis techniques in the aged adult: indications and limitations. Current Opinion in Clinical Nutrition and Metabolic Care, 12(1), 8-14. http://doi.org/10.1097/MCO.0b013e32831b9c $5 \mathrm{~b}$ 
Moderate physical activity and lean body mass | 159

World Health Organization. (1996). Research on the biochemical alterations. Brazilian Journal of menopause in the 1990s. Report of a WHO Scientific Group. World Health Organization Technical Report Series, 866, 1-107.

Physical Therapy, 11(2), 91-97.

http://doi.org/10.1590/S1413-

35552007000200002

Zhong, S., Chen, C. N., \& Thompson, L. V. (2007).

Sarcopenia of ageing: functional, structural and

Todo o conteúdo da revista Motricidade está licenciado sob a Creative Commons, exceto quando especificado em contrário e nos conteúdos retirados de outras fontes bibliográficas. 